\title{
RANCANG BANGUN TEOLOGI MULTIKULTURAL DALAM PERSPEKTIF PERJANJIAN BARU
}

\author{
GUNARYO SUDARMANTO
}

\section{PENDAHULUAN}

Diversitas manusia merupakan kekayaan sekaligus potensi konflik. Fakta di sepanjang sejarah manusia menunjukkan bahwa perbedaan etnik dan religi telah menjadikan manusia bagai serigala bagi sesamanya (homo homini lopus). Konflik horisontal yang terus terjadi, lebih disebabkan oleh sempitnya horison tentang hakikat nilai sesama sebagai akibat dari justifikasi dogmatis yang tidak seimbang. Padahal di setiap komunitas religi dan etnik senantiasa memuat urgensi menghargai kehidupan sesama manusia.

Teologi Kristen tidak meniadakan kebenaran bahwa TUHAN baik kepada semua orang (Mzm 145:8). Untuk itu pula Rasul Paulus menyerukan, "...marilah kita berbuat baik kepada semua orang, tetapi terutama kepada kawan-kawan kita seiman" (Gal 6:10). Kata terutama tidak berarti meniadakan aspek universalitasnya, melainkan pada prioritas sesuai tuntutan konteks jamannya. Mengumpulkan dasar-dasar Alkitabiah yang melandasi pemahaman tentang pentingnya membangun relasi dengan sesama, itulah yang saya sebut sebagai Teologi Multikultural. Teologi ini menekankan pada cara pandang Allah terhadap sesama manusia yang berbeda etnik dan religinya. Dengan teologi ini, orang Kristen memiliki landasan yang kokoh untuk membangun relasi dengan sesamanya dalam segala kepelbagaiannya. Dalam perspektif Perjanjian Baru setidaknya ditemukan Enam prinsip teologis yang dapat menjadi rancang bangun Teologi Multikultural. Keenam prinsip tersebut ialah: (1) Inkarnasi; (2) Universalitas soteriologi; (3) Teokrasi-presentis; (4) Universalitas Karya Roh Kudus; (5) Naturalitas Gereja sebagai tubuh Kristus; (6) Multikulturalitas kekekalan.

\section{INKARNASI}

Istilah inkarnasi merupakan bentukan kata Latin: in (masuk) dan carne (daging) yang berarti masuk ke dalam daging. Istilah ini digunakan secara teologis untuk menunjuk pada fakta "Allah menjadi manusia 
(daging) di dalam dan melalui Yesus Kristus.” Kebenaran ini bersumber dari Yohanes 1:14 khususnya pada frasa, "Firman itu telah menjadi manusia" (kai o' logoj sarx egeneto). Kata egeneto (menjadi) ditulis dalam bentuk singular, aorist, middle, indicative. ${ }^{1}$ menunjuk kepada sesuatu yang sudah pernah sungguh-sungguh terjadi secara faktual. Dengan kata lain bahwa peristiwa itu bukan sebuah metafor atau simbolis, dan hasilnya masih dapat dirasakan sampai masa sesudahnya. Hal serupa pernah terjadi pada isteri Lot menjadi tiang garam (Kej 19:26). Artinya secara faktual ia sungguh-sungguh menjadi tiang garam. Sedangkan kata sarx (sarx) yang secara harafiah berarti daging digunakan untuk menunjukkan kesungguhan kemanusiaan Yesus. Sebaliknya, kata logoj (logos) diartikan Firman menunjuk pada kesungguhan keilahian Yesus. ${ }^{2}$ Jadi dengan frasa "dan Firman itu telah menjadi manusia" Yohanes menegaskan bahwa yang sungguh-sungguh Allah telah menjadi sungguhsungguh manusia. Terutama dengan menggunakan kata sarx, Yohanes melegitimasi kesungguhan realitas kemanusiaan Yesus. Paulus juga menggunakan kata sark untuk menunjukkan hakikat manusia dengan segala kelemahannya $\left(\operatorname{Rm} 8: 3\right.$; Flp 2:7). ${ }^{3}$

Selain secara literal, kemanusiaan Yesus juga dapat dibuktikan dari aspek-aspek fisik, intelektual, emosi, kehendak dan spiritual sebagaimana ciri-ciri manusia pada umumnya. Secara fisik Yesus dilahirkan secara alamiah (Mat 1:25; Luk 2:7). Dia bertumbuh secara normal dari kanakkanak hingga menjadi dewasa (Luk 2:40). Dia merasa lapar (Mat 21:18) dan haus (Yoh 19:28). Dia mengalami penderitaan dan kematian (Yoh 19:33). Secara mental Dia membutuhkan informasi sehingga perlu bertanya (Mrk 9:21; Luk 2:46-47). Secara intelektual, Dia belajar Kitab Suci dengan nalar anak Yahudi. Secara emosi, Dia mengasihi keluarga-Nya (Yoh 19:26) dan sahabat-Nya (Mat 23:37). Dia bisa marah (Mrk 19:26), sedih (Mat 9:36). Dia juga memiliki kehendak yang berbeda dengan Bapa-Nya (Mat 26:39). Secara spiritual, Dia berdoa (Mrk 1:35), beriman dan taat kepada Bapa (Flp 2:8). Jadi, dari seluruh aspek tersebut jelas menunjukkan bahwa Yesus benar-benar manusia secara utuh. Dengan menjadi manusia Dia turut merasakan berbagai pencobaan dan penderitaan manusia supaya Dia bisa menolong manusia berdosa (Ibr 2:18, 4:16). Meski dalam segala hal

${ }^{1}$ Hasan Susanto (Peny.), Perjanjian Baru Interlinear Yunani-Indonesia (Jakarta: LAI, 2003), 476.

${ }^{2}$ Leon Morris, The New International Commentary on The New Testament: The Gospel According to John (Grand Rapdis: Eerdmans, 1977), 102.

3 William Hendriksen, New Testament Commentary: The Gospel of John (Edinburg: The Banner Truth Trust, 1959), 109. 
Dia sama dengan manusia, namun Dia tidak pernah berbuat dosa (Ibr 4:15) dan tidak pernah gagal. Yesus adalah Manusia Sejati sebagaimana keadaan manusia ketika ia diciptakan pada mulanya, sebelum jatuh ke dalam dosa. ${ }^{4}$ Karya Kristus ini menunjukkan dua kebenaran penting. Pertama, Solidaritas. Dia yang mulia sedia merendahkan diri, menjadi kecil dan lemah. Dia sedia masuk ke dalam kesakitan dan penderitaan manusia (Flp 2:6-8). Dia melakukan segalanya demi manusia. Dia memberi makan yang lapar, menyembuhkan yang sakit, mengampuni yang berdosa, menjadi kawan bagi yang tersisih, membangkitkan yang mati. Bahkan Dia juga menjadi korban ketidakadilan. Dia mati menanggung dosa manusia. ${ }^{5}$ Kedua, Identifikasi diri. Kesediaan-Nya menjadi manusia dan sedia memasuki dunia manusia merupakan bentuk identifikasi diri dengan manusia yang dilayani-Nya. Ini merupakan model yang harus ditiru misi kristiani masa kini. Mengenai hal ini, John Stott menyatakan bahwa,

Sebab jika misi kristiani harus mengikuti model misi Kristus, maka tak dapat tidak dalamnya harus tercakup tuntutan yang sama seperti yang telah dipenuhi-Nya, yaitu bahwa kita harus memasuki duniadunia orang lain... itu berarti kerelaan meninggalkan kemudahan dan kerterjaminan latarbelakang kebudayaan sendiri, agar dapat mengabdikan diri kepada kepentingan orang-orang dari latar belakang kebudayaan yang lain, yang kebutuhan-kebutuhannya mustahil dapat kita ketahui atau simak sebelumnya. Misi nyata, entah itu pekabaran Injil atau pelayanan sosial atau dua-duanya, menuntut pengidentifikasian diri dengan orang-orang dalam situasi aktual mereka. ${ }^{6}$

Prinsip solidaritas dan identifikasi diri yang dilakukan Yesus dalam masa inkanasi-Nya ini merupakan dasar Kristologis bagi hubungan yang baik dengan semua orang secara multikultur, baik multietnis maupun multireligi.

\section{UNIVERSALITAS SOTERIOLOGI}

Tujuan utama kedatangan Yesus ke dunia adalah menyelamatkan manusia berdosa. Yang dimaksudkan dengan manusia berdosa ini tentunya bukanlah bangsa Israel saja, melainkan semua bangsa, karena semua orang

\footnotetext{
${ }^{4}$ Peter Wongso, Kristologi (Malang: SAAT, 1988), 61-62.

5 John Stott, Isu-isu Global Menantang Kepemimpinan Kristiani (Jakarta: Yayasan Komunikasi Bina Kasih, 1984), 15.

${ }^{6}$ Ibid., 15-16.
} 
telah berdosa dan kehilangan kemuliaan Allah (Rm 3:23). Sejak jatuh ke dalam dosa, manusia telah menjadi musuh Allah (ectra tou qeou: Rm 5:10; Kol 1:21; Yak 4:4). Namun pada prinsipnya, Allah tidak menghendaki seorangpun binasa, maka setiap orang memiliki kesempatan untuk bertobat, yaitu mengalami pemulihan hubungan (rekonsiliasi) dengan Allah dan sesamanya. Karya keselamatan Allah di dalam dan melalui Kristus disebut juga sebagai atonement. Untuk memahami konsep mengenai karya keselamatan ini, PL menggunakan kata Ibrani rpk (khapar) yang artinya: to cover by making expiation. Sedangkan PB menggunakan kata Yunani katallagh (katallage) yang berarti reconciliation. ${ }^{7}$ Rekonsiliasi merupakan bagian sentral dari karya keselamatan Kristus yang sudah dimulai pada masa PL. Dalam PB, rasul Paulus paling banyak menguraikan pokok ini, antara lain dalam Roma 5:1011 dan 2 Korintus 5:18-20. Dalam kedua teks tersebut, Paulus memakai istilah katallage yang diartikan dengan pendamaian. Kata itu berasal dari kata kerja katallasw (katallaso), artinya: mendamaikan. PB menggunakannya dalam dua konteks, yaitu: konteks hubungan suami dan isteri, dan konteks hubungan Allah dan manusia. ${ }^{8}$ Kattallasw/ dibentuk dari kata allassw (allaso) yang artinya: mengubah (to change). Sedangkan allasw sendiri berasal dari kata allwj (allos) yang berarti: lain atau yang lain (other, another). Jadi, secara esensial, katallasw memiliki pengertian dasar mengubah menjadi lain. ${ }^{9}$ Dalam konteks karya keselamatan manusia katallasw dimaksudkan untuk mengubah manusia sebagai musuh Allah menjadi kekasih Allah (agaphtoj). Untuk maksud itu Kristus datang ke dunia yaitu menyelamatkan setiap orang yang percaya kepada-Nya (Yoh 3:16).

Karya keselamatan tersebut terbuka untuk semua orang (universal). Sebab itu, sebelum kenaikan-Nya ke sorga, Yesus memberikan Amanat Agung-Nya kepada murid-Nya untuk menjadi saksi-Nya dari Yerusalem, Yudea, Samaria dan sampai ujung bumi. Amanat ini, “...menegaskan bahwa Injil sebagai satu-satunya kebenaran universal harus disampaikan kepada segenap umat manusia pada segala tempat dan waktu (universal)." ${ }^{10}$ Selain

\footnotetext{
${ }^{7}$ Archibal A. Hodge, The Atonement (London: Evangelical Pree, 1974), 33.

${ }^{8}$ Buchel, katallagh dalam Gerhart Kittel (Ed.), Theological Dictionary of New Testament, Vol. I (Grand Rapids: Eerdmans, t.t.), 255.

${ }^{9}$ Robert L. Thomas (Ed.), New American Standard Exhaustive Concordance of The Bible (Nashville: Holman Bible Publisher, 1981), 1629, 1630, 1659.

${ }^{10}$ Elisa B. Surbakti, Benarkah Yesus Juruselamat Universal? (Jakarta: BPK Gunung Mulia, 2006), 55.
} 
berita Injil tersebut dimaksudkan untuk pemulihan hubungan dengan Allah, namun akibatnya juga akan terjadi pemulihan hubungan antar sesama manusia. Prinsip universalitas keselamatan ini merupakan dasar bagi hubungan multikultur, karena setiap orang dengan etnis dan religinya memiliki kesempatan untuk percaya kepada Kristus dan menerima keselamatan. Karena itu, hubungan multikultural haruslah dipandang dari dua perspektif sekaligus, yaitu: keharusan untuk hidup dalam damai dengan orang lain, dan memanfaatkan hubungan multikultur sebagai kesempatan untuk memberitakan kabar keselamatan kepada semua orang. Karena itu Injil juga harus diberitakan melalui aspek-aspek budaya orang lain.

\section{TEOKRASI-PRESENTIS}

Yang dimaksudkan dengan Teokrasi ialah pemerintahan Allah dimana Allah memerintah sebagai Raja dalam Kerajaan-Nya. Dengan kata lain Teokrasi berbicara mengenai kerajaan Allah yang dalam bahasa Yunani disebut basileia tou qeou (basileia tou theou). Istilah Yunani basileia dari kata basileuj (basileus) yang berarti: raja. ${ }^{11}$ Dalam pemikiran Yunani basileus menunjuk kepada seorang raja yang sah menurut hukum dan biasanya secara turun-temurun menjadi pemimpin religius atas rakyatnya. ${ }^{12}$ Sedangkan istilah basileia (basileia) yang berarti pertama: royal, power, kingship, dominion, rule." Kedua: a kingdom. Arti yang pertama menunjuk kepada kuasa atau wewenang yang dimiliki oleh seorang raja. Sedangkan yang kedua menunjuk kepada wilayah kekuasaan seorang raja.

Kemudian dalam Alkitab istilah kerajaan digunakan dalam hubungannya dengan Allah, sehingga disebut Kerajaan Allah: $\mathrm{h}$ ' basileia tou Qeou: he basileia tou theou. Istilah Kerajaan Allah itu sendiri digunakan oleh Yesus dalam pemberitaan-Nya seperti termaktub dalam Injil Sinoptis, yang juga sinonim dengan Kerajaan Sorga (Mat 4:17; 5:3; Mrk 1:15; Luk 6:20) dan Kerajaan Bapa (Mat 26:29). Istilah Kerajaan Allah dan Kerajaan Sorga secara literal tidak terdapat dalam Perjanjian Lama, sehingga pengertiannya juga belum begitu jelas dalam agama Yahudi. Namun demikian akar dan ide yang terkandung di dalamnya sudah terdapat secara samar dalam Perjanjian Lama dan dalam pengharapan iman

${ }^{11}$ B. Klappert, "King, Kingdom" dalam Colin Brown, The New International Dictionary of New Testament Theology, Vol. 2 (Grand Rapids: Zondervan, 1976), 372.

12 Kleinknecht, "basileuj in The Greek World" dalam Kittel (Ed.), Theological Dictionary of..., Vol. I, 564. 
umat Israel. Karena itu istilah Kerajaan Sorga tidak ditemukan dalam tulisan-tulisan Yahudi-Yunani, namun sudah terdapat dalam literatur Talmud (malkuth shamayim) sebagai literatur yang lebih tua. Hal itu menunjukkan bahwa pemahaman dasar tentang Kerajaan Sorga telah disimpan lama dalam idiom Yahudi. ${ }^{13}$

Jadi, kerajaan Allah dapat berarti: pemerintahan Allah, kekuasaan Allah, dan kedaulatan Allah yang bersifat universal (bnd Mzm 103:19; 145:11,13; Dan 2:37; Luk 19:11-12). Secara terminologis Alkitabiah pengertian kerajaan Allah lebih menunjuk kepada kedudukan-Nya sebagai raja atau pemerintahan-Nya dan kedaulatan-Nya. ${ }^{14}$ Kerajaan Allah ini menunjuk kepada Kristus sebagai Raja yang sudah datang, memulai kerajaan-Nya dan akan datang di masa mendatang (future). Karena itu basileia tou theou tidak hanya dimengerti sebagai The Kingdom of God (Kerajaan Allah) melainkan God's Kingship (Kepemerintahan Allah). Kingship of God lebih menunjuk kepada sebuah situasi yang luas yang meliputi seluruh kehidupan yang di dalamnya Allah memerintah sebagai Raja. Dalam pengertian ini Allah menjadi pemilik dari seluruh kehidupan pada masa kini dan masa yang akan datang. ${ }^{15}$ Eka Darmaputera menambahkan bahwa Kerajaan Allah merupakan terminologi dalam teologi Kristen yang menunjuk kepada, "suatu keadaan atau kenyataan dimana Allah dengan spenuhnya akan memerintah dan memberlakukan kehendakNya, yaitu keadilan, kebenaran, perdamaian dan kesejahteraan yang menyeluruh bagi seluruh umat manusia." "Itu berarti Kerajaan Allah tidak hanya bersifat futuris, melainkan juga memuat dimensi presentis. Hal itu sudah dinyatakan ketika Yohanes Pembaptis berseru, "Bertobatlah, sebab Kerajaan Sorga sudah dekat!" (Mat 3:2). Frasa sudah dekat diterjemahkan dari kata Yunani hggiken (eggiken) yang merupakan bentuk perfek aktif indikatif dari eggidzw (eggidzo) yang berarti: to come near, approach, or draw nigh." W.E. Best menjelaskan pengertian dasar dari ketiga kata Inggris tersebut sebagai berikut:

${ }^{13}$ George Eldon Ladd, Crucial Question About The Kingdom of God (Grand Rapids: Eerdmans, 1952), 121-122.

${ }^{14}$ George Eldon Ladd, Injil Kerajaan (Malang: Gandum Mas, 1999), 21-23.

15 Weinata Sairin, Victor I. Tanya, Eka Darmaputera, "Berbagai Dimensi Kerukunan Hidup Umat Beragama" dalam Weinata Sairin (Peny.), Kerukunan Umat Beragama Pilar Utama Kerukunan Berbangsa (Jakarta: BPK Gunung Mulia, 2006), 18.

${ }^{16}$ Eka Darmaputera, "Tugas Panggilan Bersama Agama-agama di Indonesia" dalam. J. Garang (Peny.), Peranan Agama-agama dan Kepercayaan Terhadap Tuhan yang Maha Esa Dalam Negara Pancasila yang Membangun (Jakarta: BPK Gunung Mulia, 1996), 141. 
There is much discussion over the following statement in the King James translation of the Bible: "the Kingdom of heaven is at hand" (Matt 3:2; 4:17; 10:7). The Greek verb in those verses is eggiken, perfect active indicative of eggidzo, which means to come near, approach, or draw nigh. When we observe the basic English meaning of these three verbs, we can better determine the definition of eggidzo. "Come" means to come toward or away from something, to pass from one point to one nearer. "Draw" means to pull, drag, draw, or move toward. "Approach" means to come or go near or nearer in either place or time. The accurance of eggidzo in its perfect active indicative form in each reference where it is used proves that the kingdom has not arrived, but it has approach or come near. ${ }^{17}$

Dengan demikian dapat dikatakan bahwa Kerajaan Allah itu memang sudah dekat atau sama dengan belum sampai. Namun tidak berarti masih sangat jauh sehingga sama sekali tidak dapat dilihat dan dirasakan kehadirannya. Maksud dari kata eggiken adalah bahwa kehadirannya telah begitu dekat dan sangat dapat dirasakan. Bentuk perfek yang digunakan menegaskan bahwa kerajaan yang dimaksudkan dalam nubuatan PL telah benar-benar tergenapi.

Presensi Kerajaan Allah itu semakin jelas ketika Yesus memulai pelayanan-Nya di Galilea dan menyatakan, "Waktunya telah genap, Kerajaan Allah sudah dekat. Bertobatlah dan percayalah kepada Injil!" (Mrk 4:15). Kata Yunani yang diterjemahkan dengan "waktu" adalah kata kairoj (kairos) yang berarti saat atau waktu tertentu, bukan kronoj (kronos) yaitu waktu yang berlangsung terus menerus. Kairos itulah yang dipakai Yesus untuk menunjukkan penggenapan di dalam Diri-Nya. Herman Ridderbos menjelaskan pengertian kairos sebagai berikut:

Therefore, kairos means the great moment of commencement of the great future appointed by God in His counsel, and announced by the prophets. By the side of "is at hand" there is already the "is fulfilled." No doubt the two expressions shoult be understood in connection with each other. "At hand" in expression "is at hand" does not mean the same thing as "has come," "is present," as clearly appears from the purpose of John's preaching. The expression "the time is fulfilled" will thus have to be understood as the indication that the threhold of the great future has been reached, that the door has been opened, and that the prerequisites of the

${ }^{17}$ W.E. Best, Christ's Kingdom Is Future, Vol. II (Houston, Texas: South Belt Assembly of Christ, t.t), 159. 
realization of the divine work of consummation are present; so that now the concluding divine drama can start. ${ }^{18}$

Jadi, waktunya telah genap berarti bahwa melalui kehadiran Yesus "masa yang akan datang" sedang dimulai. Hal itu lebih ditegaskan oleh Yesus ketika Ia berkhotbah di Nazaret (Luk 4:16-30). Dalam ibadah di Sinagoge itu Ia membaca nubuat dari kitab Yesaya 61:1-2 mengenai tahun rahmat Tuhan. Pada saat itulah Yesus menegaskan: "Pada hari ini genaplah nas ini...” (ay 21). Dengan penegasan tersebut, Yesus sedang menunjuk Diri-Nya sendiri sebagai penggenapan dari nubuatan Yesaya. Itu berarti bahwa Person yang diurapi Tuhan dan yang disertai Roh Tuhan, seperti yang dimaksudkan oleh Yesaya, ialah Yesus sendiri. Dialah yang dimaksudkan yang akan memberitakan kabar baik kepada orang miskin, pembebasan kepada tawanan, mencelikkan yang buta, membebaskan yang tertindas, dan memberitakan tahun rahmat Tuhan.

Hal tersebut ditegaskan kembali oleh Yesus ketika menjawab pertanyaan murid-murid Yohanes Pembaptis tentang jatidiri-Nya sebagai Mesias. Yesus menjawab pertanyaan itu dengan menyebutkan tindakantindakan Mesianis-Nya, yaitu: “...orang buta melihat, orang lumpuh berjalan, orang kusta menjadi tahir, orang tuli mendengar, orang mati dibangkitkan dan kepada orang miskin diberitakan kabar baik" (Luk 7:1822). Meskipun Yesus hanya menyebutkan karya-Nya, namun hal itu sekaligus mengindikasikan jatidiri-Nya sebagai Mesias. Dalam hal ini nyata kesatuan karya dan Person Mesias dalam Diri Yesus.

Selanjutnya, presensi Kerajaan Allah diperjelas oleh tanda-tanda yang dinyatakan Yesus melalui pengajaran dan karya-karya-Nya. Secara umum ada enam tanda yang menunjukkan presensi Kerajaan Allah, yaitu:

Pertama, pemberitaan kabar baik kepada orang miskin. Tanda ini dinyatakan tiga kali oleh Yesus, yaitu: dalam khotbah di Nazaret (Luk 4:18), dalam jawaban-Nya atas keraguan Yohanes Pembaptis di penjara (Mat 11:5; Luk 7:22), dan dalam ucapan bahagia (Mat 5:3; Luk 6:20). Kata miskin yang dimaksudkan adalah pertama-tama menunjuk kepada orang desa (am-haarezt). Mereka adalah penduduk Israel yang kurang memahami Hukum Taurat, karena tidak mendapatkan pengajaran semestinya dari orang Farisi dan ahli Taurat. Mereka tidak diperhatikan dan dianggap berperilaku tidak senonoh, sehingga dianggap berada di luar keselamatan.

${ }^{18}$ Herman Ridderbos, The Coming of The Kingdom (Philadelphia: Presbyterian and Reform Publishing Company, 1973), 48. 
Dengan demikian di dalam kemiskinan jasmani terkandung juga kesusahan rohani yang terus menantikan datangnya keselamatan atas dirinya. ${ }^{19}$

Kata miskin juga bisa diartikan sebagai orang yang mengalami kesulitan jasmani, menanggung sengsara, teraniaya dalam masyarakat dan mengeluh di bawah kejahatan sosial orang-orang yang egois. Tetapi mereka juga adalah orang yang rendah hati, lembut hati, senantiasa menantikan keselamatan yang dijanjikan Allah kepada umat-Nya. Kepada merekalah Injil Kerajaan Allah diberitakan sebagai penggenapan janji keselamatanNya. ${ }^{20}$ Pengertian tersebut juga berkaitan dengan pernyataan Yesus dalam Matius 5:3, "Berbahagialah orang yang miskin di hadapan Allah, karena merekalah yang empunya Kerajaan Sorga." Dalam ayat itu, kata miskin lebih bersifat rohani daripada jasmani. Frasa "merekalah yang empunya Kerajaan Sorga" berarti Kerajaan Sorga menjadi milik mereka dalam arti rohani. Sebagai contoh, Yesus mengajarkan perumpamaan tentang orang Farisi dan pemungut cukai (Luk 18:9-14). Keduanya bersama-sama berdoa di Bait Allah. Dalam doanya orang, Farisi sangat bangga dengan segala kebaikan rohaninya. Sedangkan pemungut cukai dengan hancur hati menyadari keberdosaannya. Tentang pemungut cukai itu Yesus berkata: "orang ini pulang ke rumahnya sebagai orang yang dibenarkan Allah dan orang lain itu tidak" (ay 4). ${ }^{21}$ Mengomentari ayat tersebut Charles L. Allen menyatakan: "The first key to God's Kingdom is another type of poverty... the poverty which is a key to God's Kingdom is realization that, though we posses all things, without God all our things are nothing." 22 Itulah aspek utama yang diperhatikan Yesus, sehingga mereka perlu mendengarkan Injil agar mereka mengalami keselamatan dari dosa.

Kedua, kehadiran Kerajaan Allah ditandai dengan Pengampunan dosa. Yesus menegaskan kembali nubuat Yesaya tentang, "Pembebasan bagi tawanan dan orang yang tertindas" (Luk 4:19). Pernyataan itu hanya dapat dimengerti dalam hubungannya dengan pengampunan dosa, karena terkait erat dengan tahun rahmat Tuhan atau tahun Yobel. Di tahun itu, menurut tradisi Israel, seorang yang miskin dan telah menjadi budak harus dibebaskan dari segala hutangnya dan dimerdekakan (bnd. Im 25:39, dst; Yeh 46:17). Searah dengan nubuatan tersebut, Yesus memberikan

\footnotetext{
${ }^{19}$ Ulrich Beyer, Garis-garis Besar Eskatologi Dalam Perjanjian Baru (Jakarta: BPK Gunung Mulia, 1982), 16.

${ }^{20}$ Herman Ridderbos dan Baarlink, Pemberitaan Yesus Menurut Injil Sinoptis (Jakarta: BPK Gunung Mulia, 1975), 72-75.

${ }^{21}$ Peter Wongso, Hermeneutika Eskatologi (Malang: SAAT, 1989), 91. 1970), 130-131.

${ }^{22}$ Charles L. Allen, God's Psichiatry (New Jersey: Fleming H. Revell Company,
} 
pengampunan dosa agar orang yang tertawan dan tertindas oleh dosanya dilepaskan dan diampuni. Matthew Henry dalam komentarnya menyatakan: "The Gospel is a proclamation of liberty, like that to Israel in Egypt and in Babylon. It is a deliverence from the worst of thraldoms, which all those shall have the benefit of that are willing to make Christ their Head."23 Pembebasan yang utama ialah pembebasan dari dosa. Karena itu Yesus memberitakan tentang pengampunan dosa dan melakukan pengampunan dosa (Mrk 2:5). Tindakan tersebut merupakan proklamasi ke-Allahan-Nya dimana Ia menunjukkan hak prerogatif Allah untuk mengampuni manusia berdosa. Untuk itu Ia bergaul dengan orang-orang yang dianggap paling berdosa seperti: pemungut cukai dan wanita pezinah, karena mereka juga berhak masuk ke dalam Kerajaan Allah. Kepada para pemimpin agama Yahudi, Yesus menegaskan, "pemungut-pemungut cukai dan perempuanperempuan sundal akan mendahului kamu masuk ke dalam Kerajaan Allah" (Mat 21:31). Ayat itu menunjukkan sifat kekinian dari Kerajaan Allah, karena orang-orang berdosa itu sedang menjadi warga Kerajaan Allah. Itu berarti Yesus menyatakan bahwa Kerajaan Allah sudah hadir dan dimulai di bumi. ${ }^{24}$

Ketiga, Yesus melakukan Mujizat. Matius 8:17; 11:5; Lukas 7:16 mendaftarkan tindakan kemesiasan Yesus sebagaimana dinubuatkan Yesaya 35:5b; 29:18-19 dimana "orang buta melihat, orang lumpuh berjalan, orang kusta menjadi tahir, orang tuli mendengar dan orang mati dibangkitkan." Esensi dari mujizat tersebut ialah penyataan Kerajaan Allah sebagai tindakan penyelamatan oleh Mesias. Jadi, dengan melakukan mujizat, sebenarnya Yesus sedang menunjukkan kehadiran-Nya sebagai Raja yang berkuasa. ${ }^{25}$

Keempat, Pengusiran setan. Secara eksplisit Yesus sendiri telah menyatakan hubungan langsung antara pengusiran setan dengan kehadiran Kerajaan Allah. Ia berkata, "Jika Aku mengusir setan dengan kuasa Roh Allah, sesungguhnya Kerajaan Allah sudah datang kepadamu" (Mat 12:28; Luk 11:20). George Eldon Ladd menyatakan, "Tindakan pengusiran rohroh jahat membuktikan bahwa Kerajaan Allah sudah datang dan sedang bekerja di antara umat manusia. Pengusiran roh jahat itu sendiri merupakan

\footnotetext{
${ }^{24}$ Donald Guthrie, Teologi Perjanjian Baru (Jakarta: BPK Gunung Mulia, 1993), 26.

${ }^{25}$ Ridderbos dan Baarlink, Pemberitaan Yesus Menurut..., 36-38.
} 1979), 1425

${ }^{23}$ Matthew Henry, Matthew's Henry Commentary (Grand Rapids: Zondervan, 
pekerjaan Kerajaan Allah."26 Jelaslah bahwa pengusiran setan oleh Yesus membuktikan kekalahan kuasa setan atas kuasa Allah yang telah hadir di dalam dan melalui Yesus. Dengan kata lain, terusirnya setan menyatakan kehadiran Kerajaan Allah.

Kelima, Perumpamaan. Untuk mengajarkan tentang kerajaan Allah, Yesus kerapkali menjelaskannya melalui sebuah perumpamaan, yaitu cerita yang diambil dari kehidupan manusia sehari-hari dan dirancang untuk menggambarkan kebenaran utama dari apa yang akan diberitakan. Perumpamaan begitu penting, sehingga menguasai hampir sepertiga dari pengajaran Yesus. ${ }^{27}$ Dalam Markus 4 dan Matius 13 terdapat kumpulan perumpamaan tentang rahasia Kerajaan Allah. Melalui perumpamaanperumpamaan tersebut, Yesus menyatakan kehadiran Kerajaan Allah sebagai revolusi Allah dalam sejarah. David Wenham dalam bukunya The Parables of Jesus: Pictures of Revolution menjelaskan sebagai berikut:

...in proclaiming the kingdom of God, Jesus was announcing the coming of God's revolution and God's new world, as promised in the Old Testament. God was at last intervening, Jesus declared, to establish his reign over everything, to bring salvation to his people and renewal and reconciliation to the world. But fortunetely Jesus did not announce his message in such general theological terms, he announced it primarily through vivid, concrete parables. ${ }^{28}$

Jadi, melalui perumpamaan yang disampaikan, Yesus menegaskan bahwa Kerajaan Allah telah dinyatakan dan hadir dalam sejarah manusia masa kini. Keenam, Peristiwa di sekitar Yesus melebihi kehebatan peristiwa dalam PL. Yesus menyatakan hal itu ketika berkata, "sesungguhnya yang ada di sini lebih besar daripada Yunus" dan "lebih daripada Salomo" (Mat 12:41-42). Peristiwa Yunus dan pertobatan orang Niniwe merupakan peristiwa yang menakjubkan. Tetapi Yunus hanya memberitakan tentang kebenaran Allah, sedangkan Yesus adalah kebenaran itu sendiri. Demikian juga dengan hikmat Salomo yang begitu tinggi, sehingga mempesona setiap orang yang mendengarnya. Namun, Salomo tidak dapat memberikan hikmatnya kepada siapapun, sedangkan Yesus adalah Hikmat itu sendiri dan memberikan kepada siapa saja yang datang kepada-Nya serta menyelamatkannya. Karena itu Ia menegaskan, 1987), 56

${ }^{26}$ George E. Ladd, A Theology of The New Testament (Grand Rapids: Eerdmans,

${ }^{27}$ A.M. Hunter, Menafsirkan Perumpamaan-perumpamaan Yesus (Jakarta: BPK Gunung Mulia, 2000), 1, 11.

28 David Wenham, The Parables of Jesus: Pictures of Revolution (London: Hodder \& Stoughton, 1989), 25. 
"Sesungguhnya banyak nabi dan orang benar ingin melihat apa yang kamu lihat, tetapi tidak melihatnya dan ingin mendengar apa yang kamu dengar, tetapi tidak mendengarnya" (Mat 13:17). ${ }^{29}$ Artinya, di dalam dan melalui Yesus terjadi peristiwa-peristiwa yang melebihi peristiwa sebelumnya. Itu disebabkan Yesus sendiri ialah Mesias yang oleh-Nya Allah melawat umatNya dengan kasih-Nya sebagaimana telah dijanjikan sebelumnya (Luk 7:16; Mat 11:2-6). Dengan kedatangan Yesus berarti masa eskatologis sudah mulai diwujudkan pada masa kini.

Selain bukti-bukti kehadiran Kerajaan Allah pada masa kini tersebut di atas, Kerajaan Kristus juga dapat dipahami dalam dua aspek pengertian, yaitu: regnum potentiae dan regnum gratiae. Yang dimaksud dengan regnum gratiae adalah jabatan Kristus sebagai Raja Rohani atas umat-Nya atau Gereja-Nya. Kerajaan ini bersifat rohani yang didasarkan pada karya penebusan Kristus. Kerajaan rohani ini sudah ada pada masa sekarang mapun masa yang akan datang. ${ }^{30}$ Sedangkan yang dimaksud dengan regnum potentiae adalah kekuasaan Kristus atas alam semesta yaitu pemerintahan-Nya secara providensial dan yuridis atas segala sesuatu dalam hubunganya dengan Gereja. Lebih lanjut Berkhof menjelaskan bahwa, sebagai Raja alam semesta, Sang Pengantara memimpin dan menentukan setiap pribadi individual, dari kelompok sosial, dan bangsabangsa, untuk menentukan pertumbuhan, penyucian sedikit demi sedikit, dan kesempurnaan akhir dari umat-Nya yang telah Ia tebus dengan darahNya... Kristus sekarang mengatur jalan hidup setiap individu dan bangsa yang termasuk dalam Gereja yang telah disatukan oleh darah-Nya... ${ }^{31}$

Jadi, dari aspek regnum potentiae, pemerintahan Kristus atas alam semesta berkuasa mengatur segala bangsa untuk melindungi umat-Nya. Dalam hal ini nampak hubungan tak terpisahkan antara umat-Nya dengan bangsa-bangsa. Sebab itu Gereja tidaklah seharusnya berusaha memisahkan diri dari bangsa-bangsa (multikultur), sebaliknya harus mengintensifkan hubungan dengan bangsa-bangsa. Dalam hal ini Gereja menyatakan keharmonisan sosial sebagai bagian dari rencana perwujudan Kerajaan Allah dalam aspek kekinian. Gereja memiliki tanggung jawab sosial yang menyatukannya dengan masyarakat. Gereja dan masyarakat tidak dapat dipisahkan melainkan saling melengkapi. ${ }^{32} \mathrm{H}$. Henry Meeter menegaskan

\footnotetext{
${ }^{29}$ Beyer, Garis-garis Besar..., 22.

${ }^{30}$ Louis Berkhof, Teologi Sistematika 3: Doktrin Kristus (Jakarta: LRII, 1998), 234-242.

${ }^{31}$ Ibid., 242-243.

32 Ernst Troeltsch, Protestanism and Progres, A History of the Relation of Protestanism to the Modern World (Beacon: Beacon, 1958), 57.
} 
bahwa sorga dibawa ke dalam material (dunia nyata). Dimensi rohani menerangi dunia materi (sosial) supaya terjadi pemulihan. Tuhan mendelegasikan orang percaya untuk membangun dan memelihara tatanan sosial. ${ }^{33}$ Teokrasi presentis dalam aspek inilah yang menjadi dasar orang percaya untuk berelasi sebaik-baiknya secara multietnis dan multireligi.

\section{UNIVERSALITAS KARYA ROH KUDUS}

Pemberitaan karya Allah diteruskan oleh Roh Kudus ke seluruh dunia di segala abad. Roh Kudus adalah utusan Kristus untuk mengaplikasikan karya Kristus kepada semua manusia. Roh Kudus inilah yang dijanjikan Kristus sebagai yang akan memberi kuasa untuk menjadi saksi Kristus (Kis 1:8). Dinamika Roh Kudus yang memampukan para murid Kristus untuk menjadi saksi-saksi Kristus sampai ke ujung bumi. Dalam hal ini Roh Kudus menindak lanjuti penugasan Kristus untuk menjadikan sekalian bangsa murid-Nya (Mat 28:19-20). Dengan tugas ini menunjukkan adanya aspek universalitas karya Roh Kudus itu. Pada peristiwa Pentakosta, universalitas tersebut mulai memanifestasi dalam bentuk bahasa-bahasa dari berbagai etnis (Partia, Media, Elam, Mesopotamia, Yudea, Kapadokia, Pontus, Asia, Frigia, Pamfilia, Mesir, Libia, Roma, Yahudi, Kreta, dan Arab; Kis 2:8-11). Jadi, Roh Kudus yang mendinamisasi orang percaya untuk memberitakan Injil kepada segala bangsa (panta ta ethne). H. Berkhof sebagaimana dikutip oleh Abineno menyatakan sebagai berikut:

Roh Yesus Kristus-yaitu Roh yang mengandung kuasa yang membebaskan dan yang membaharui-sedang bekerja di segala tempat,di mana manusia dilepaskan dari keganasan alam, negara, warna kulit, kasta, kelas, kelamin, kemiskinan, penyakit, kebodohan dan lain-lain. ${ }^{34}$

Lebih lanjut Abineno menegaskan bahwa karya Roh Kudus tidak hanya terbatas pada Gereja, melainkan mencakup seluruh dunia. ${ }^{35}$ Atas dasar itu, orang yang telah ditebus oleh karya Kristus dan menerima Roh

\footnotetext{
${ }^{33}$ H. Henry Meeter, The Sovereignty of The Social Sphere (Grand Rapids: Baker Book House, 1975), 125.

${ }^{34}$ J.L.Ch. Abineno, Roh Kudus dan Pekerjaan-Nya (Jakarta: BPK Gunung Mulia, 1982), 144.

${ }^{35}$ Ibid., 145.
} 
Kudus dalam dirinya pastilah didorong untuk terus berkomunikasi dengan orang lain yang beda etis dan agama menjadi saksi Kristus bagi mereka.

Selain itu, Roh Kudus juga memberi buah dalam hidup orang percaya berupa: kasih, sukacita, damai sejahtera, kesabaran, kemurahan, kebaikan, kesetiaan, kelemahlembutan dan penguasaan diri (Gal 5:23). Buah Roh ini merupakan potensi pada diri orang percaya untuk diaktualisasikan dalam relasinya dengan orang lain: baik teman seiman maupun beda iman. Misalnya, istilah kasih yang diterjemahkan dari agape berarti: love, concern, interest, sacred meal shared by the early church (kasih, kepedulian, minat, makanan kudus yang dibagikan oleh Gereja mula-mula). ${ }^{36}$ Makna yang jelas dari agape adalah kasih dan kepedulian yang mencakup kasih kepada semua orang. J. Lengkong menyimpulkan,

Kasih sebagai buah Roh tidak bersikap diskriminatif dan memperlakukan orang-orang lain dengan keprihatinan yang mendalam... Rasa cemburu yang banyak merusak hubungan antar pribadi, antar golongan dan antar umat beragama, akan dengan sendirinya ditinggalkan." 37

Hal ini juga menjadi dasar untuk melakukan kebaikan kepada yang beda etnis dan religinya.

\section{NATURALITAS GEREJA SEBAGAI TUBUH KRISTUS}

Septuaginta menggunakan istilah Yunani ekkalew (ekkaleo) yang artinya: memanggil keluar. Dari kata Yunani ini, Perjanjian Baru menggunakan kata ekklesia (ekklesia) sebagai bentukan dari kata ek (ek) dan kalew (kaleo) yang berarti: dipanggil keluar. Kata ini dimengerti dalam hubungannya dengan karya Kristus yang telah menjadi Juruselamat manusia berdosa. Sehingga secara esensial kata ekklesia dimengerti sebagai "persekutuan orang yang telah dipanggil keluar dari dunia ini untuk menjadi milik Allah." 38 Dengan demikian pengertian ekklesia juga menunjukkan keterikatan dengan Allah di dalam dan melalui Kristus.

36 Barclay M. Newman, A Concise Greek-English Dictionary Of The New Testament (London: United Bible Societies, 1971), 2.

37 Josias L. Lengkong, Jihad Kristen: Adakah kesamaan Jihad Islam dan Jihad Kristen? (Jakarta: Yayasan Misi Global Kalimatullah, 2003), 306-307. 1976), 555.

${ }^{38}$ Louis Berkhof, Systematic Theology (Edinburg: The Banner of Truth Trust, 
Sebab itu ekklesia juga dimengerti sebagai jemaat Allah dengan maksud yang sama seperti qahal yahwe dalam Perjanjian Lama.

Pemahaman Yesus tentang jemaat Allah nampak dalam misi pelayanan dan pengajaran-Nya yang berkesinambungan dengan pemahaman Perjanjian Lama. Yesus memfokuskan pelayanan-Nya kepada orang Yahudi yang disebut-Nya sebagai "domba-domba yang hilang dari umat Israel" (Mat 15:24) yang secara esensial sama dengan umat Allah. Namun kemudian Yesus memperluas pengertian domba yang hilang juga dikenakan kepada murid-Nya yang tercerai-berai (Luk 12:32; Mrk 14:27; bnd. Zak 13:7). Meskipun Yesus menujukan misi keselamatan-Nya kepada orang Yahudi, namun Ia juga menyadari bahwa mereka akhirnya akan menolak-Nya. Sebab itu terjadi transformasi pengertian umat Allah yang tidak saja ditujukan kepada umat Israel melainkan juga kepada para muridNya dan semua orang yang percaya kepada-Nya (bnd. Mat 3:9; Luk 3:8). Yesus menggunakan istilah ekklesia tidak dimaksudkan menunjuk kepada suatu organisasi, tetapi sekelompok orang yang dianggap-Nya sebagai milik-Nya dan diwakili oleh para murid-Nya. ${ }^{39}$

Jadi, Gereja pada hakikatnya ialah umat Allah atau jemaat Allah yaitu orang-orang yang telah dipanggil keluar dari dunia melalui karya Kristus untuk mengalami persekutuan dengan Dia pada masa kini dan masa yang akan datang. Gereja bersifat universal karena meliputi seluruh orang percaya di muka bumi. Karena itu, Gereja juga dituntut agar kehadirannya di dunia ini menjadi representasi Allah dengan turut memproklamasikan keselamatan dari Allah melalui Yesus Kristus.

Dengan demikian tidak dapat dipisahkan antara Kristus dan Gereja. Kristus adalah Kepala Gereja dan Gereja adalah umat-Nya. Dia memerintah di dalam dan melalui Gereja-Nya. Gereja sebagai umat yang kudus yang telah dipanggil ke luar dari dunia, namun diutus kembali ke dalam dunia. Karenanya, Gereja berada di dalam konteks dunia. Sebagai bagian integral dari konteks dunia, maka Gereja harus berkorelasi dengan konteks sosial dan kultural di tengah masyarakat sekitarnya. Sebagai Kepala Gereja yang memerintah kerajaan-Nya, Kristus juga tidak menginginkan Gereja-Nya ke luar dari konteks sosial masyarakat. Donald B. Kraybill menegaskan,

Kitab-kitab Injil tidak memandang kerajaan itu sebagai sesuatu yang terasing dari bagian masyarakat lainnya, baik secara geografis maupun sosial. Yesus tidak menganjurkan kita menghindar atau menarik diri dari kehidupan sosial. Ia juga tidak mengasumsikan

${ }^{39}$ Donald Guthrie, Teologi Perjanjian Baru, Jilid 3 (Jakarta: BPK Gunung Mulia, 1992), 27-28, 34 . 
bahwa kerajaan dan dunia terpisah dalam wilayah-wilayah yang terbagi tegas. Aksi kerajaan itu berlangsung di tengah-tengah kehidupan sosial. ${ }^{40}$

Dengan demikian, natur alamiah Gereja membuatnya tidak bisa tidak berinteraksi aktif dengan konteksnya. Interaksi tersebut mewujud dalam karya-karya bersama dengan orang lain yang tidak seetnis atau seagama. George V. Pixley menyebutkan lebih konkrit demikian,

Dalam pengertian abstrak dan umum kerajaan Allah dalam Alkitab berarti satu masyarakat yang adil, makmur dan yang memandang semua manusia sederajat. Dalam arti konkret, kerajaan Allah mendorong berbagai proyek historis dalam bermacam-macam keadaan. Dalam dua momen permulaan kerajaan berarti pembebasan, satu perjuangan melawan sistem-sistem penjejangan sosial yang memeras kaum pekarya Israel. ${ }^{41}$

Di sinilah Gereja harus kreatif dalam melaksanakan panggilannya untuk percaya dan melayani secara seimbang di tengah dunia. Gereja dituntut tanggung jawab yang besar untuk melibatkan diri sepenuhnya dalam kehidupan sosial yang sama nilainya dengan aspek rohani. ${ }^{42}$ Jadi, Kristus yang telah memanggil Gereja-Nya ke luar dari dunia, namun mengutusnya kembali ke dalam dunia, menghendaki agar Gereja-Nya berinteraksi melalui karya nyata di tengah masyarakat. Hakikat naturalitas Gereja inilah yang juga dapat menjadi dasar untuk berinteraksi dengan multietnis dan multireligi.

\section{MULTIKULTURALITAS KEKEKALAN}

Karya penebusan Kristus yang diteruskan oleh dinamika karya Roh Kudus telah melahirkan Gereja Perjanjian Baru yang bersifat multikultural. Hingga perkembangannya saat ini Gereja terus menjadi semakin multikultural, seperti disinyalir bahwa,

Dalam tahun-tahun belakangan ini maka persoalan budaya dan pluralismenya sudah menjadi masalah yang sangat besar di seluruh dunia (hal ini juga berhubungan dengan migrasi dan globalisasi).

${ }^{40}$ Donald B. Kraybill, Kerajaan Yang Sungsang (Jakarta: BPK Gunung Mulia, 1993), 3.

${ }^{41}$ George V. Pixley, Kerajaan Allah (Jakarta: Gunung Mulia, 1998), 92.

${ }^{42}$ Albert Terril Rasmussen, Christian Social Ethics, Exerting Christian Influence (Englewood: Prenctice, 1956), 70-72, 266. 
Banyak Gereja sekarang memasuki situasi di mana Gereja memiliki jemaat yang berasal dari budaya yang beragam dan karenanya Gereja terdorong untuk menjadi lebih multi-cultural. ${ }^{43}$

Kondisi Multikulturalitas Gereja ini akan terus berlanjut hingga kekekalan. Pada masa eskatologis, dimana Gereja-Nya telah mengalami pengudusan sempurna, setelah kedatangan Kristus, Sang Kepala Gereja, untuk kedua kalinya, maka Gereja-Nya juga memasuki masa kemuliaan di hadapan tahta Bapa yang kekal. Di sanalah multikulturalitas Gereja menyemarakkan suasana kemuliaan, sebagaimana digambarkan oleh Yohanes dalam kitab Wahyu 7:9-10 sebagai berikut:

"Kemudian daripada itu aku melihat: sesungguhnya, suatu kumpulan besar orang banyak yang tidak dapat terhitung banyaknya, dari segala bangsa dan suku dan kaum dan bahasa, berdiri di hadapan tahta dan di hadapan Anak Domba, memakai jubah putih dan memegang daun-daun palem di tangan mereka. Dan dengan suara nyaring mereka berseru: "Keselamatan bagi Allah kami yang duduk di atas tahta dan bagi Anak Domba."

Multikulturalitas kekekalan di hadapan Anak Domba (Kristus) ini juga menjadi landasan Kristologis bagi orang percaya masa kini bahwa Allah sangat memberi tempat bagi multikulturalitas umat-Nya. Ini menjadi motivasi bagi Gereja masa kini untuk terus memberitakan kabar baik kepada segala bangsa dan suku bangsa (multietnis).

\section{PENUTUP}

Diversitas humanitas mesti dipandang sebagai kreatifitas Allah yang patut dihargai sebagaimana Allah menghargainya sebagai gambar dan rupa-Nya sendiri. Diskriminasi humanitas justru bukti sikap antagonis terhadap otoritas penciptanya. Radikalisme doktrin yang melulu berorientasi pada kebenaran vertikal harus dibarengi dengan pemahaman horisontalnya. Kebenaran sejati justru menjadi utuh ketika kedua aspek tersebut diposisikan secara proporsional. Perbedaan bukan alasan untuk saling melawan dan menghancurkan, karena kasih kepada Tuhan dan sesama bukanlah kebenaran yang dapat dipisahkan sama sekali.

Allah sendiri telah berbuat baik kepada semua orang sesuai hakikat Diri-Nya sendiri sebagai Pencipta segalanya. Allah juga menghendaki agar

${ }^{43}$ Agus Gunawan Satyaputra, Gereja, Budaya dan Misi dalam Jurnal Teologi: Stulos (Bandung: STTB, 2002), 100. 
manusia, yang telah diciptakan dalam gambar dan rupa-Nya, saling melakukan perbuatan baik. Semua manusia memiliki tanggung jawab bersama selama kehidupannya di dunia ini, sehingga dibutuhkan solidaritas dengan sesama. Melalui interaksi yang baik justru dimungkinkan adanya point of contact bagi Injil, sehingga dapat terjadi transformasi kesadaran terhadap hakikat kebenaran Injil yang meresap ke segala aspek hidup manusia seperti garam mengasinkan dunia yang tawar (Mat 5:13). Teologi Multikultural melandasi sikap Kristen untuk berelasi dengan semua orang dalam segala bentuk perbedaannya tanpa kehilangan jati diri (keunikan) kekristenannya. 